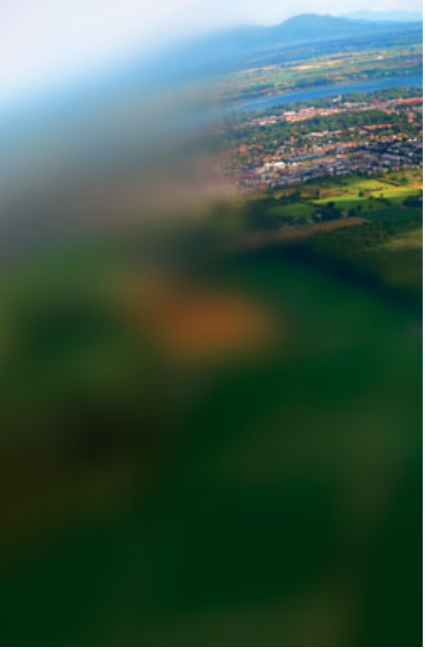

\title{
Materials challenges and opportunities for enhancing the sustainability of automobiles
}

\author{
Gregory A. Keoleian and John L. Sullivan
}

\begin{abstract}
Materials play a major role in defining the sustainability performance of automobiles throughout their materials-production, manufacturing, use, and end-of-life stages. Materials production and manufacturing raise many sustainability issues, including resource scarcity and materials sourcing, energy and carbon intensity, and materials efficiency in parts fabrication. In the use stage, materials properties such as density and strength directly affect materialsmass requirements, which influence two dominant sustainability parameters for vehicles: fuel economy and service life. For conventional vehicles, the operation segment of the use stage accounts for about $85 \%$ of the total life-cycle energy consumption and greenhouse-gas emissions. Consequently, powertrain technologies and efficiencies as well as fuel-cycle processes control these impacts. Future trends in vehicle electrification will shift the magnitude and distribution of life-cycle impacts and the effectiveness of materials strategies for improving sustainability, such as lightweighting. In many cases, the materials-production stage could become a greater determinant in life-cycle impacts. With current vehicle end-of-life management infrastructure, $85 \%$ of materials are recyclable, but recovery of plastics and segregation of metal alloys represent opportunities for improvement. Life-cycle assessment and cost analysis provide the most comprehensive methods for evaluating the sustainability of materials strategies. Using a life-cycle framework, this article highlights the current and future materials challenges and opportunities driving vehicle sustainability performance.
\end{abstract}

\section{Introduction}

Automobiles provide tremendous mobility to consumers and have added considerably to the standard of living in the developed world. On the other hand, vehicles are resource-intensive products that significantly impact the environment throughout their lifetime. Each year in the United States, cars and light-duty trucks collectively consume about 17.3 EJ of energy during operation, comprising $\sim 60 \%$ of U.S. transportation energy use and $\sim 17 \%$ of total U.S. energy consumption. As of 2009, 684 million cars were registered worldwide, with $19.4 \%$ (132 million) in the United States, even though the United States represents only $4.5 \%$ of the world's population. ${ }^{1}$ Vehicle ownership in 2009 was 828 vehicles per thousand people in the United States compared to around 46 per thousand in China. ${ }^{1}$ As automobile use grows in developing countries, this will pose even greater sustainability challenges in terms of materials and energy resources, as well as environmental impacts. This article explores the role materials play in influencing the sustainability of automobiles from a life-cycle perspective.
The life-cycle assessment framework shown in Figure 1 provides a systematic method and set of metrics for analyzing the environmental sustainability performance of vehicles over their useful life. This article focuses on the environmental dimension of sustainability, which also has social and economic dimensions. A typical vehicle, including its approximately 20,000 parts, can be examined across its major life-cycle stages (and substages): materials production; manufacturing (comprising part fabrication and vehicle assembly); use (comprising vehicle operation and service); and finally, vehicle end-of-life (EOL) management. Of these stages and substages, two dominate the environmental sustainability performance of a vehicle: materials production and vehicle operation. Moreover, these two are interlinked in the design phase of vehicle production by two design features: (1) materials composition and mass and (2) powertrain efficiency and fuels. The key materialssustainability issues described herein are also highlighted in the white boxes in Figure 1. 


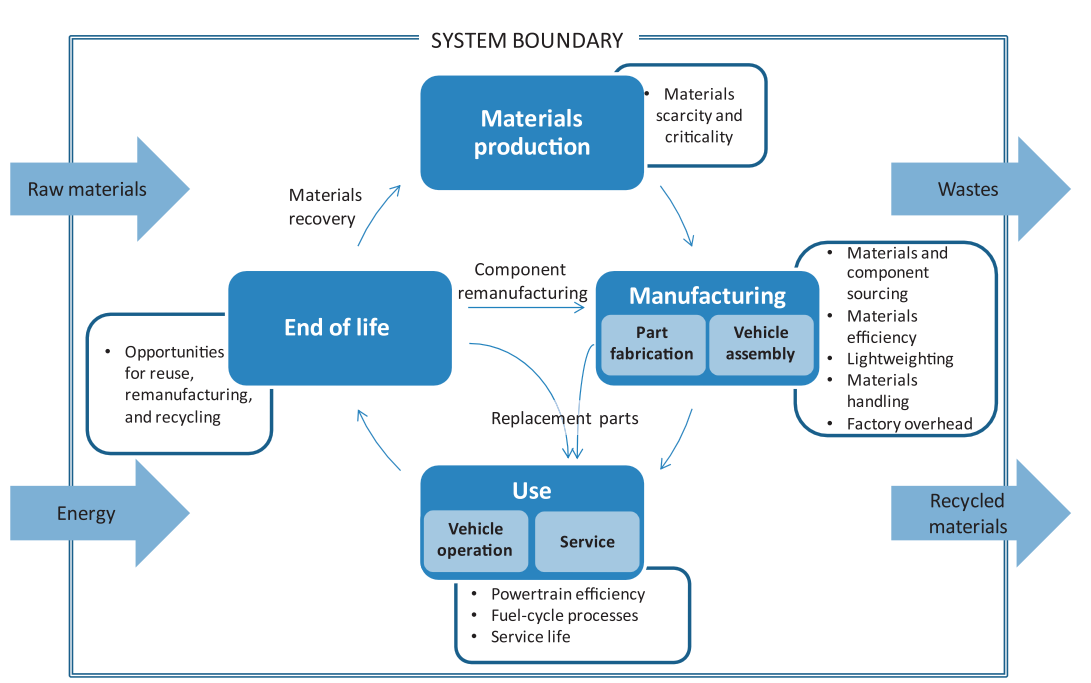

Figure 1. The life-cycle framework for a vehicle examines the environmental impacts from every stage of its life.

durability, aesthetics, materials and fabrication costs, and recyclability.

The automotive industry is responsible for a large portion of materials consumption globally. As an example, in 2009, the U.S. automotive industry accounted for $12.9 \%$ of total U.S. steel consumption (7.3 million tonnes), $24.7 \%$ of U.S. aluminum consumption (1.7 million tonnes), $72.8 \%$ of U.S. lead consumption (1.0 million tonnes), $19.1 \%$ of U.S. iron consumption (1.1 million tonnes), 13.1\% of U.S. alloy steel consumption $(310,000$ tonnes), $21.0 \%$ of U.S. stainless steel consumption (310,000 tonnes), $22.7 \%$ of U.S. zinc consumption (180,000 tonnes), 10.8\% of U.S. copper consumption (290,000 tonnes; copper data are for 2008, as no 2009 data were available), and $40.0 \%$ of U.S. consumption of non-tire rubber products $(340,000$ tonnes). ${ }^{3}$

Lightweighting, which aims to preserve

Key materials-related strategies for improvement include reduction in materials intensity, materials efficiency in manufacturing, lightweighting, and recovery options from reuse to recycling. Life-cycle assessment provides an analytical framework to ensure that these strategies reduce the total vehicle life-cycle burdens and impacts and avoid shifting them from one vehicle system or life-cycle stage to another. For example, vehicle lightweighting with an aluminum-intensive body would reduce fuel consumption in the use stage but increase burdens from materials production relative to those of a conventional vehicle. $^{2}$

The objectives of this article are twofold: first, to highlight the environmental sustainability challenges relating to materials for automotive applications and, second, to identify opportunities for improvement. The article focuses on the vehicle life-cycle stages and their interactions that are most strongly influenced by the materials that embody the vehicle.

\section{Scope of materials usage in the automotive industry}

Materials-related life-cycle impacts of a vehicle are ultimately shaped by its materials composition and mass. The average materials compositions of U.S. automobiles for model years 1995, 2000, and 2009 are provided in Table I. In 1995, steel accounted for $55.5 \mathrm{wt} \%$, aluminum $6.3 \mathrm{wt} \%$, and plastics $6.5 \mathrm{wt} \%$. By 2009, the corresponding values were $54.4 \mathrm{wt} \%$, $8.3 \mathrm{wt} \%$, and $9.8 \mathrm{wt} \%$, respectively. Most of aluminum's inroads have come at the expense of iron castings. The table shows that the materials composition of vehicles has shifted only slightly over the past 15 years. Materials selection and specification for vehicles is a complex process governed by a broad set of requirements including functional performance and physical/chemical properties, structural integrity, safety, vehicle size but at a lower weight, could significantly reduce the environmental footprint of vehicles. However, market trends in vehicle fleets in the past two decades have largely offset any gains in fuel economy from lightweighting. From 1987 to 2010, despite lightweighting initiatives, the average vehicle weight increased by $24 \%$, because of the growth in the sport utility vehicle (SUV) market share. Over the same period, horsepower increased by over $86 \%$, and acceleration [reported as the time required to go from rest to $60 \mathrm{mph}$ (or to $100 \mathrm{~km} / \mathrm{h}$ outside the United States)] increased by $27 \%$. Had vehicle weights remained at 1988 levels, model year 2010 cars could have achieved a $12 \%$ higher fuel economy; trucks, a $13 \%$ increase. $^{4}$ Nevertheless, inroads are being made by lightweight materials in vehicles such as high-strength steel, aluminum, and fiber-reinforced composites. Other factors influence materials consumption as well, such as market trends of the past few years showing a shift back to smaller vehicles, presumably because of higher fuel prices and other economic factors.

\section{Materials-production stage}

Key sustainability issues arising from materials production include energy intensity, carbon intensity, and materials scarcity.

\section{Energy and greenhouse-gas intensities of materials production}

The energy and greenhouse-gas (GHG) intensities of materials production, in units of megajoules per kilogram $(\mathrm{MJ} / \mathrm{kg})$ and kilograms of carbon dioxide equivalents per kilogram ( $\mathrm{kg}$ of $\mathrm{CO}_{2} \mathrm{e} / \mathrm{kg}$ ), respectively, are key parameters that define materials-production burdens and impacts for vehicles. The materials-production stage includes resource extraction (mining, petroleum extraction), materials or feedstock processing (ore sizing, chemical feedstock production), and refining or synthesis (smelting, steelmaking, polymerization). Typical values for 
Table I. Average materials composition for a North American domestic light vehicle, model years 1995, 2000, and 2009.

\begin{tabular}{|c|c|c|c|c|c|c|}
\hline \multirow[t]{2}{*}{ Material } & \multicolumn{2}{|c|}{1995} & \multicolumn{2}{|c|}{2000} & \multicolumn{2}{|c|}{2009} \\
\hline & kg & $\begin{array}{c}\text { Mass } \\
\text { percentage }\end{array}$ & kg & $\begin{array}{c}\text { Mass } \\
\text { percentage }\end{array}$ & kg & $\begin{array}{c}\text { Mass } \\
\text { percentage }\end{array}$ \\
\hline Regular steel & 739 & $44.1 \%$ & 751 & $42.4 \%$ & 681 & $38.3 \%$ \\
\hline $\begin{array}{l}\text { High- and medium- } \\
\text { strength steel }\end{array}$ & 147 & $8.8 \%$ & 185 & $10.5 \%$ & 238 & $13.4 \%$ \\
\hline Stainless steel & 23 & $1.4 \%$ & 28 & $1.6 \%$ & 31 & $1.8 \%$ \\
\hline Other steels & 21 & $1.2 \%$ & 12 & $0.7 \%$ & 14 & $0.8 \%$ \\
\hline Iron castings & 211 & $12.6 \%$ & 196 & $11.1 \%$ & 93 & $5.3 \%$ \\
\hline Aluminum & 105 & $6.3 \%$ & 122 & $6.9 \%$ & 147 & $8.3 \%$ \\
\hline Magnesium castings & 2 & $0.1 \%$ & 4 & $0.2 \%$ & 5 & $0.3 \%$ \\
\hline Copper and brass & 23 & $1.4 \%$ & 24 & $1.3 \%$ & 29 & $1.6 \%$ \\
\hline Lead & 15 & $0.9 \%$ & 16 & $0.9 \%$ & 20 & $1.1 \%$ \\
\hline Zinc castings & 9 & $0.5 \%$ & 6 & $0.3 \%$ & 4 & $0.2 \%$ \\
\hline Powder metal parts & 13 & $0.8 \%$ & 16 & $0.9 \%$ & 19 & $1.0 \%$ \\
\hline Other metals & 2 & $0.1 \%$ & 2 & $0.1 \%$ & 2 & $0.1 \%$ \\
\hline $\begin{array}{l}\text { Plastics and plastic } \\
\text { composites }\end{array}$ & 109 & $6.5 \%$ & 130 & $7.3 \%$ & 174 & $9.8 \%$ \\
\hline Rubber & 68 & $4.0 \%$ & 75 & $4.3 \%$ & 96 & $5.4 \%$ \\
\hline Coatings & 10 & $0.6 \%$ & 11 & $0.6 \%$ & 15 & $0.9 \%$ \\
\hline Textiles & 19 & $1.1 \%$ & 20 & $1.1 \%$ & 24 & $1.4 \%$ \\
\hline Fluids and lubricants & 87 & $5.2 \%$ & 94 & $5.3 \%$ & 99 & $5.6 \%$ \\
\hline Glass & 44 & $2.6 \%$ & 47 & $2.6 \%$ & 42 & $2.4 \%$ \\
\hline Other materials & 29 & $1.7 \%$ & 32 & $1.8 \%$ & 41 & $2.3 \%$ \\
\hline Total & 1676 & $100.0 \%$ & 1770 & $100.0 \%$ & 1776 & $100.0 \%$ \\
\hline
\end{tabular}

Sources: Reference 3, p. 65, and 2009 data from Reference 1, p. 4.16. and $\mathrm{C}_{2} \mathrm{~F}_{6}$ ) were reduced by $88 \%$ between 1990 and 2009. ${ }^{7}$

The values shown in Table II, taken from the GREET 2.7 model (The Greenhouse Gases, Regulated Emissions, and Energy Use in Transportation model developed at Argonne National Laboratory), ${ }^{5}$ are the best available life-cycle data for North American vehicle modeling. Significant variations occur depending on technology age, processes, fuels, and electricity sources. The sourcing of materials can strongly change the environmental impacts. For example, aluminum produced in Asia has significantly higher greenhouse-gas emissions $(21.9 \mathrm{~kg}$ of $\mathrm{CO}_{2} \mathrm{e} / \mathrm{kg}$ of $\mathrm{Al}$ ) than that produced in North America (10.7 $\mathrm{kg}$ of $\mathrm{CO}_{2} \mathrm{e} / \mathrm{kg}$ ) or Latin America (7.1 kg of $\left.\mathrm{CO}_{2} \mathrm{e} / \mathrm{kg}\right){ }^{8}$ The difference is determined largely by differences in the carbon intensity of the electricity employed, which is generated mainly by coal in Asia but includes hydroelectricity in Latin America. ${ }^{8}$ energy and GHG intensities for the materials-production stage are reported in Table II.

The dramatic differences between the values for production of primary and secondary (recycled) materials illustrate the substantial potential benefits of recycling. These are particularly significant for materials such as aluminum, nickel, and lead. Because most recycled metals are recovered in the reduced state, recovery processes for secondary materials are generally less energy-intensive than those for virgin materials.

Energy intensity is highly correlated with carbon-emissions intensity, because most carbon emissions arise from the combustion of fuels. In the case of plastics, a significant fraction of the energy input is embodied in the materials (feedstocks) and does not contribute directly to the carbon intensity, unless the plastic is burned. Some materials-production processes result in emissions of greenhouse gases other than carbon dioxide, such as perfluorocarbons from aluminum production and sulfur hexafluoride from magnesium production. Process improvements have targeted these emissions. In the case of aluminum production, for example, perfluorocarbons $\left(\mathrm{CF}_{4}\right.$

\section{Resource sourcing and scarcity}

Materials supply is ultimately determined by the availability and concentration of primary resources in Earth's crust (i.e., the reserves, $R$, of economically extractable resources) and the rates of global annual production $(P)$. Some mineral resources are relatively abundant, as characterized by the adequacy of mineral reserves (high $R / P$ ratio). For example, for aluminum (bauxite) and iron and steel (iron ore), this ratio easily exceeds 100 years. Other materials are much scarcer (as detailed further in the article by Graedel et al. in this issue). A recent study explored the resource supply for key elements, including those used in advanced battery materials and permanent magnets for vehicles. ${ }^{9}$ Cobalt; lithium; and rare-earth (RE) elements including lanthanum, cerium, praseodymium, and neodymium are used in electric-vehicle batteries. Neodymium, praseodymium, dysprosium, and samarium are used in permanent magnets to develop high-power-density motors for electric vehicles. Cerium is also used in autocatalytic converters to catalyze the oxidation of carbon monoxide and accounted for $9 \%$ of all U.S. RE consumption in 2008. Of the REs listed, five (dysprosium, 
Table II. Production energy and greenhouse-gas (GHG) emissions for various materials from the GREET 2.7 transportation life-cycle model. ${ }^{5}$

\begin{tabular}{|c|c|c|}
\hline Material & Total energy (MJ/kg) & GHG emissions $\left(\mathrm{kg}\right.$ of $\left.\mathrm{CO}_{2} \mathrm{e} / \mathrm{kg}\right)$ \\
\hline \multicolumn{3}{|r|}{ 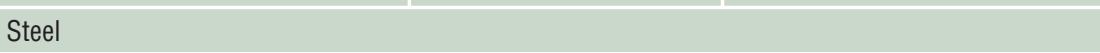 } \\
\hline Primary & 27 & 3.6 \\
\hline Secondary & 19 & 1.2 \\
\hline Cast iron & 33 & 0.5 \\
\hline \multicolumn{3}{|l|}{ Aluminum } \\
\hline Primary (ingot) & 149 & 10 \\
\hline Secondary (ingot) & 13 & 0.9 \\
\hline \multicolumn{3}{|l|}{ Lead } \\
\hline Primary & 29 & 0.9 \\
\hline Secondary & 5 & 0.5 \\
\hline \multicolumn{3}{|l|}{ Nickel } \\
\hline Primary & 148 & 12 \\
\hline Secondary & 37 & 2.9 \\
\hline \multicolumn{3}{|l|}{ Copper } \\
\hline Primary & 111 & 8.5 \\
\hline \multicolumn{3}{|l|}{ Plastics } \\
\hline Polypropylene & 49 & 3.7 \\
\hline Polyester & 87 & 6.9 \\
\hline High-density polyethylene & 53 & 4.1 \\
\hline Glass-fiber-reinforced plastic & 85 & 4.8 \\
\hline Carbon-fiber-reinforced plastic & 160 & 9.7 \\
\hline Glass & 20 & 1.6 \\
\hline Fiber glass & 21 & 1.5 \\
\hline Rubber & 44 & 3.2 \\
\hline \multicolumn{3}{|l|}{ Nickel hydroxide } \\
\hline Primary & 104 & 8.2 \\
\hline Secondary & 6 & 0.5 \\
\hline Potassium hydroxide & 11 & 0.8 \\
\hline \multicolumn{3}{|l|}{ Cobalt oxide } \\
\hline Primary & 148 & 12 \\
\hline Secondary & 37 & 3 \\
\hline Zinc & 121 & 8.8 \\
\hline Magnesium & 372 & 29 \\
\hline Platinum & 199 & 16 \\
\hline Zirconium & 226 & 16 \\
\hline Rare earth & 336 & 27 \\
\hline Manganese & 121 & 8.8 \\
\hline Nafion 117 sheet & 24 & 1.8 \\
\hline Nafion dry polymer & 24 & 1.8 \\
\hline Polytetrafluoroethylene & 113 & 8.4 \\
\hline
\end{tabular}

Note: Updated values for new and existing materials were developed by the Center for Sustainable Systems ${ }^{6}$ and are currently under review for inclusion in the GREET model. neodymium, terbium, europium, and yttrium), as well as indium, were assessed as most critical in the short term. "Criticality" is a measure that combines importance of the resource to the economy and risk of supply disruption. For example, Toyota is sufficiently concerned about the supply of rare-earth magnet materials for its hybrid vehicles that it is developing induction motors that do not need permanent magnets. ${ }^{10}$

Earth's crust contains sufficient REs and other critical resources to meet projections for the coming decades. However, the current supply might not satisfy the demand in the short (0-5 years) or medium (5-15 years) terms. One problem is that mining operations have significant lead times to start up, from 2 to 10 years. Currently, the rareearth metals used in magnets and batteries are mined almost exclusively in China (95\% of all REs). This is changing, with significant mining capacity expected to come online by 2015 in California, Australia, and other places and to provide an almost 50\% increase in RE supply. ${ }^{9}$

Magnets in vehicle motors can contain up to $1 \mathrm{~kg}$ of neodymium and/or praseodymium. Additionally, approximately $5.5 \%$ of the weight of these magnets is dysprosium. Neodymium and dysprosium are the only REs that have been identified as critical. In the near term, the needs for lanthanum and cerium are also expected to become near-critical, but they should not be critical once the increased mining comes online. Praseodymium and samarium are not expected to be at risk for supply disruptions.

Lithium is largely mined in Chile, in shallow brine pools. However, in the next five years, additional lithium production is expected to be developed (by current lithium producers) in the western United States, Argentina, and Chile. In the next five years, these developments could account for an approximately $85 \%$ increase in lithium supply. ${ }^{9}$ Lithium is used as a cathode or electrolyte in advanced batteries for longer-range electrified vehicles. 
Although demand for lithium could increase significantly, its supply is ample to meet demand well beyond midcentury. ${ }^{11-13}$ Cobalt, used in nickel-metal hydride (NiMH) batteries for current hybrid electric vehicles, is not expected to reach a critical supply level in the next 15 years. ${ }^{9}$

Currently, recycling of REs in permanent magnets is not economically viable. Although automotive batteries are recycled, the lithium in the batteries is rarely harvested; instead, other more valuable materials are collected, and the hazardous waste is properly disposed. Further, REs used in NiMH batteries are not recycled and end up in slag that is typically used for road beds. More efficient use, reuse, and recycling of these materials would clearly lower world demand for new extraction.

\section{Bio-based materials}

As a potentially more-sustainable alternative to conventional materials, several bio-based materials and products have been introduced in the automotive industry, including bio-based and soy-based resins, biofillers in plastics, natural fiber fillers in plastics, and fabrics. ${ }^{14}$ For example, Ford Motor Company demonstrated the first use of soy-based foam for seats in 2008 and for headliners in 2010. ${ }^{15}$ A new head-restraint foam in which $25 \%$ of the polyol is replaced by soy was also recently launched. ${ }^{15}$

Bio-based composites can be made from biological fibers, such as grass, corn straws, flax, hemp, kenaf, jute, pineapple leaf fiber, and sisal, mixed with some sort of polymer matrix. These composites are $25-30 \%$ stronger than glass-fiber-based composites of the same weight, their fracture is nonbrittle (important for automotive applications), and their fibers take much less energy to produce (approximately one-quarter of the energy by weight for kenaf compared to glass). ${ }^{16}$ (See the article in this issue by Duflou et al. for more information on bio-based polymer composites.)

\section{Manufacturing stage}

The manufacturing stage of the vehicle life cycle comprises two separate operations: part and component manufacturing and vehicle assembly. The former involves shape-forming processes such as stamping, casting, forging, extrusion, and plastic molding, along with joining operations such as gluing, welding, and fastening. The latter encompasses assembling vehicle components into a car, as well as painting, anodizing, and galvanizing the vehicle surfaces. These two operations are typically performed at different facilities, with separate overhead costs.

In terms of energy and carbon intensities, the manufacturing stage contributes a small fraction (typically $4-5 \%$ ) of the life-cycle totals, ${ }^{17,18}$ but it can have significant indirect impacts on materials production. In fact, the materials efficiency in the manufacturing stage is a key factor influencing materials sustainability. The scrap rates for manufacturing processes can vary from as high as $40 \%$ for stamping to $5 \%$ for plastic molding. Although industrial scrap steel and aluminum are highly recycled, their scrap rates do impact the materials-production stage of the vehicle life cycle. For example, if it takes $5 \mathrm{~kg}$ of sheet aluminum to make a 3-kg stamped part, the vehicle's life cycle is charged for all $5 \mathrm{~kg}$ of environmental impacts associated with aluminum production. This is because it takes energy to make sheet aluminum, whether it is recycled or not. If it is recycled, then that metal comes to the vehicle manufacturer with its own set of environmental burdens. Note that modeling of material recycling and allocation of the impacts related to the use of recyclable materials are controversial issues in life-cycle assessment. ${ }^{19}$ Moreover, the specific allocation rules used can significantly influence the outcome of life-cycle assessments.

\section{Use stage}

The use stage can be divided into two parts: operation and service (maintenance and repair). This discussion focuses on operation because its contributions to the vehicle life-cycle energy and emissions are almost 100 times greater than those of service. The life-cycle primary energy consumption, based on a 120,000 mile (193,000 km) service life, is compared in Figure 2 for three midsized vehicle categories. For each category, the energy burden is broken into (1) the operation part of the use stage, which accounts for $84-88 \%$ of a vehicle's life-cycle energy consumption, and (2) the vehicle cycle, which is the sum of everything else, namely, materials production, manufacturing, the service part of the use stage, and vehicle end of life. Clearly, the operation part of the use stage represents a prime opportunity for improving the overall sustainability of vehicles.

Approaches to improve the environmental footprint of operation include using lightweight materials, making vehicles smaller, and developing advanced powertrains. However, tradeoffs must be kept in mind when implementing any of these approaches. For

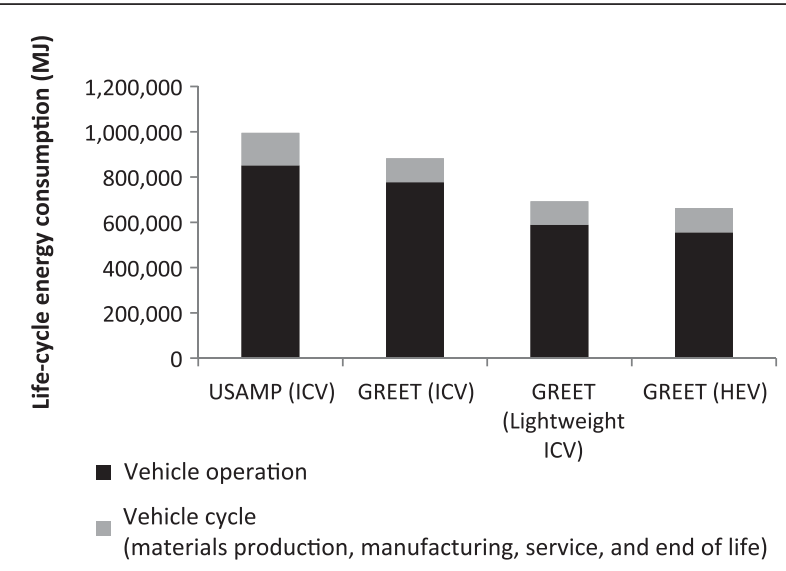

Figure 2. Comparison of life-cycle energy consumption results for passenger vehicles with a 120,000-mile (193,000-km) service life [U.S. Automotive Materials Partnership (USAMP) internal-combustion vehicle (ICV) reported in References 20 and 21; GREET ICV, Lightweight ICV, and hybrid electric vehicle (HEV) computed using GREET 2.7 and 1.8, Argonne National Laboratory]. 
example, the life-cycle energy of a vehicle generally decreases when it is made lighter, but the amount of the decrease depends on the approach used to decrease the vehicle weight, as demonstrated by the following mathematical analysis.

The life-cycle energy (LCE) of a vehicle is the sum of the energy consumption from each of the stages in Figure 1

$$
\mathrm{LCE}=E_{\mathrm{mp}}+E_{\mathrm{mf}}+E_{\mathrm{op}}+E_{\mathrm{mr}}+E_{\mathrm{eol}},
$$

where $\mathrm{mp}$ denotes materials production; $\mathrm{mf}$, part manufacturing and vehicle assembly; op, vehicle operation; $\mathrm{mr}$, vehicle maintenance and repair (i.e., service); and eol, vehicle end of life.

If a vehicle of total mass $p_{\mathrm{T}}$ is made lighter by materials substitution, then the change in LCE is dominated by the changes in the materials-production and operation terms ${ }^{22}$ and can, to a good approximation, be written as

$$
\Delta \mathrm{LCE}=\left(\frac{\mathrm{d} E_{\mathrm{mp}}}{\mathrm{d} p_{\mathrm{T}}}+\frac{\mathrm{d} E_{\mathrm{op}}}{\mathrm{d} p_{\mathrm{T}}}\right) \Delta p_{\mathrm{T}} .
$$

The energy required to operate a vehicle over its lifetime under the conditions of a fixed drive cycle (for example, city or highway) can be written as

$$
E_{\mathrm{op}}=\frac{1}{\varphi}\left(A p_{\mathrm{T}}+B\right) \times \operatorname{LTDST} \times \mathrm{LHV},
$$

where $A$ characterizes the part of the fuel consumption that scales with the mass of the vehicle and $B$ is the corresponding parasitic loss (aerodynamic drag, tire and chassis losses). LTDST is the lifetime distance driven, LHV is the lower heating value for the fuel, and $\varphi$ is the fuel production efficiency. The quantities $A$ and $B$ are expressed per unit distance driven.

The materials-production energy for the vehicle is given by

$$
E_{\mathrm{mp}}=\sum_{i} \frac{p_{i} E_{i}^{\prime}}{C_{i}}
$$

where $E_{i}^{\prime}$ is the materials-production energy per unit mass of material $i ; p_{i}$ is the mass of material $i$ on the vehicle; and $C_{i}$ is the production efficiency, which is the mass fraction of the input of material $i$ that goes into the final part.

For the case of replacing material $a$ by material $b$, the change in mass of the vehicle is related to amount of $a$ removed and $b$ added: $\Delta p_{\mathrm{T}}=\Delta m_{a}+\Delta m_{b}=\Delta m_{\mathrm{a}}(1-f)$, where $f$ is the substitution factor representing the relative mass of material $b$ needed to replace a functionally equivalent unit of material $a$. The change in LCE, including both $E_{\mathrm{mp}}$ and $E_{\mathrm{op}}$, is obtained by substituting Equations 3 and 4 into Equation 2:

$$
\begin{aligned}
\Delta \mathrm{LCE}= & {\left[\left(E_{a}^{\prime} / C_{a}-f E_{b}^{\prime} / C_{b}\right) /(1-f)+\frac{A}{\varphi}\right.} \\
& \times \mathrm{LTDST} \times \mathrm{LHV}] \Delta p_{\mathrm{T}} .
\end{aligned}
$$

Clearly, Equations 2 and 5 demonstrate that, when the lighter material takes more energy to produce, there is a tradeoff between the materials-production and operation stages of the life cycle. More elaborate treatments of this approach have been conducted by Geyer ${ }^{12}$ for greenhouse-gas emissions. His treatment includes the effects of secondary weight savings and materials recycling.

As an example of the application of Equation 5, suppose that a manufacturer wishes to improve the fuel economy of one of its vehicles by replacing steel by aluminum to reduce the vehicle weight. Based on vehicle-simulation programs for a D-class vehicle (a six-passenger vehicle with a curb weight of around $1500 \mathrm{~kg})$, the constant $A$ has the value $3.72 \times 10^{-5} \mathrm{l} /(\mathrm{kg} \mathrm{km})$. Using $C_{\text {steel }}=C_{\text {aluminum }}=1, f=0.55, \varphi=0.80$ (corresponding to reformulated low-sulfur gasoline), $E_{\text {steel }}^{\prime}=33.1 \mathrm{MJ} / \mathrm{kg}$ and $E_{\text {aluminum }}^{\prime}=145.2 \mathrm{MJ} / \mathrm{kg}$ (both from the GREET 2.7 model $^{5}$ ), $\mathrm{LHV}=32.0 \mathrm{MJ} / 1$ (for gasoline), and LTDST $=240,000 \mathrm{~km}$ in Equation 5 gives $\Delta \mathrm{LCE}=104-357=-253 \mathrm{MJ}$ for a $1-\mathrm{kg}$ reduction of vehicle weight. In this case, a reduction in vehicle LCE is realized.

However, the assumption of $C_{\text {steel }}=C_{\text {aluminum }}=1$ implies $100 \%$ production efficiencies in making both steel and aluminum parts. In reality, it takes around $10 \mathrm{~kg}$ of steel or aluminum to stamp a 5.5 -kg metal part, so $C_{\text {steel }} \approx C_{\text {aluminum }} \approx 0.55$; the rest is scrap, often referred to as offal. Taking this factor into account, for a $1-\mathrm{kg}$ vehicle weight reduction, $\triangle \mathrm{LCE}$ becomes $188-357=$ -169 MJ. Although this case also demonstrates a reduction in LCE, it is considerably less than that calculated for perfect production efficiencies.

Both examples clearly show that there is a tradeoff between materials production and vehicle operation when lightweighting through materials substitution is employed, as the lighter material generally requires more energy to produce. Further, the operational efficiency of the vehicle assumed in this example is that of a conventional D-class vehicle. For higher-efficiency vehicles such as compression-ignited direct-injection diesels $\left(A=1.56 \times 10^{-5}\right)$, the operational term is considerably smaller, and hence, the benefit of weight reduction through materials substitution is much smaller. In principle, $\triangle \mathrm{LCE}$ could even be positive upon a weight reduction.

Energy is not the only life-cycle inventory metric of interest. Greenhouse-gas (GHG) emissions are also an important consideration. Hence, if the fuel used to power the vehicle were based solely on cellulosic ethanol, which has a lower carbon footprint than gasoline, then the GHG emissions in operation of the vehicle would decrease considerably, and the life-cycle change in GHG emissions through the materials-substitution scenario just discussed would be positive.

It is clear that such estimates of changes in life-cycle impacts depend on the parameters employed. Additional relevant considerations include credits for recycling (a controversial issue) and secondary weight savings.

Individual choices also matter at the broader systems level. Vehicle size and model selection by consumers ultimately determines the materials consumption for the automotive sector. Consumers often drive oversized passenger vehicles, which can be considered a materials and energy inefficiency. A single driver commuting to work in a large SUV is an obvious mismatch between need and utility. The average occupancy 
for automobiles in the United States is around 1.6 and represents underutilized capital. Better household vehicle fleet composition and utilization to match trip activities could result in fuel savings and ultimately reduced automotive materials consumption. ${ }^{23}$

\section{End-of-life stage}

The EOL management of retired automobiles includes several resource-recovery processes. Parts and components are reused (e.g., tires) or remanufactured (e.g., engines, motors, transmissions), and materials are recycled following dismantling, shredding, and separation of nonferrous and ferrous metals. A key parameter that impacts resource flows is the vehicle service life. The median life for new 1970-model cars was 11.5 years compared to 16.9 years for 1990 -model vehicles, whereas light-truck age has remained constant at $15-16$ years over this period. ${ }^{1}$

Automobiles are among the most-recycled consumer products. Manufacturers such as General Motors Company and Ford Motor Company report that their new vehicles are 85\% recyclable (by weight). ${ }^{24,25} \mathrm{~A}$ European Union End-of-Life Vehicles Directive sets targets for reuse, recycling, and recovery of vehicles and their components that has pushed manufacturers to further enhance vehicle recyclability. ${ }^{26}$

The established vehicle-recycling infrastructure is effective in recovering ferrous and nonferrous metals, but significant amounts of auto-shredder residues consisting of plastics, rubber, glass, and other nonmetals are not recycled and are disposed in landfills. About $95 \%$ of EOL vehicles enter the auto-recycling infrastructure. ${ }^{27} \mathrm{~A}$ majority of these vehicles are initially processed by a dismantler, who removes components for reuse or remanufacturing, before sending the "hulk" (the remaining portion of the vehicle) to a shredder. Shredders recover about $95 \%$ of the ferrous and nonferrous metals in the vehicle. Various methods including mechanical separation, energy recovery, and thermochemical processes have been developed to sort or process plastics and foams from auto-shredder residue, but they are practiced on only a very limited basis. ${ }^{28}$ A study of the U.S. Automotive Recycling Centers published in 2001 determined that $84 \%$ of the mass of retired vehicles is recycled, although it was acknowledged that this estimate is likely to be high. ${ }^{29}$ This percentage includes recycled metals, other materials, and fluids as well as reused parts.

One of the challenges facing materials recycling, especially in the United States, is profitability. In the United States, auto recycling is entirely profit-driven, in contrast to Europe or Japan, where it is driven by the policy/regulatory environment and a lack of available landfill space. The recovery of metals is highly profitable, but that of plastics, especially those recovered from vehicles, is not. If vehicles become less reliant on ferrous materials as a result of lightweighting with aluminum and magnesium, recycling is likely to become more profitable, as aluminum and magnesium command higher prices in the scrap market. A key challenge for these industries is to develop an infrastructure for recycling alloys back into high-value applications such as closed-loop recycling of aluminum body panels.

Jody et al..$^{28}$ discussed three different metrics for vehicle recyclability, all based on the percentage of the vehicle weight that is recycled. In our view, such metrics are flawed, because if aluminum were used to replace some of the steel, for example, the calculated recyclability of the vehicle would decrease, even though the two metals are equally recycled. This is because the amount of nonrecyclable material has remained the same whereas the weight of recycled materials has decreased. As alternative environmentally relevant metrics, we suggest choosing a suitable base case as a reference and tracking (1) the change in mass of material required to provide the same service, (2) the amount of the vehicle entering the waste stream, and (3) the change in the mass of waste over time.

\section{Policy impacts on materials and the vehicle life cycle}

The vehicle life cycle is governed by a complex mesh of policies and regulations. In the United States, for example, the Mining Law of 1872 governs the prospecting and mining of minerals on federal public lands. Recent legislation proposed in Congress would establish royalties on mining operations that could increase the price of primary metals, which could increase the market for secondary metals and encourage recycling.

One critique of the proposed U.S. legislation is that it could simply shift mining out of the country. Weaker regulations governing manufacturing operations in developing countries have already impacted sustainability. Weak or unenforced laws lower costs and are, in part, responsible for a shift in materials production from the United States to China, which has carbonintensive electricity and lacks stringent pollution controls. This has become an important issue in the sourcing of rare earths for magnet applications. In contrast, the vehicle-recycling regulations in Europe were instrumental in promoting greater attention to resource recovery throughout the vehicle cycle.

Fuel-economy standards are currently the most critical regulations impacting the vehicle life-cycle performance in the United States. However, these standards, including the 2012-2016 fuel-economy standards and the proposed 20172025 standards, do not address the vehicle-production stage, which is expected to make a greater contribution to the lifecycle burdens as fuel economy improves. Carbon regulation, which could serve as a more systematic mechanism to lower life-cycle impacts, is also stalled in the United States. Without a comprehensive market or regulation for carbon, emissions can simply be shifted from the use stage to vehicle production.

\section{Conclusions}

Materials and energy are the two most significant inputs for vehicle systems, and current vehicle fleets are heavily dependent on nonrenewable resources for both of them. Unlike nonrenewable energy resources, which are exhausted by their use, many materials resources can be recovered and reutilized in the economy through reuse, remanufacturing, and recycling. 
Recovery of metals during end-of-life management is better for vehicles than for most product systems, but recovery of nonmetals is not. Materials industries have opportunities to continue to improve materials-production efficiencies, recover secondary materials, and reduce impacts from virgin resources.

The vehicle life cycle and associated materials selection, sourcing, and design decisions represent a complex large-scale optimization problem with multiple objectives, constraints, and stakeholders, often with competing interests. As pressures for materials resources increase because of new markets for vehicles and increasing demands from other sectors, more sophisticated life-cycle design methods and more advanced vehicle-remanufacturing and -recycling infrastructures will be required to solve the sustainability challenges faced by the auto industry. Ultimately, providing sustainable mobility for a growing population of seven billion people requires dramatic innovations by the materials and automotive industries; international commitments and policy for addressing greenhouse-gas emissions; and a more informed consumer base that understands basic sustainability concepts and factors vehicle size, fuel economy, and other environmental attributes into their vehicle purchasing and driving decisions.

\section{Acknowledgments}

Funding from the National Science Foundation's Materials Use Science Engineering and Society (MUSES) Project, Grant CMMI 0628162, and the Department of Energy U.S.-China Clean Energy Research Center (CERC) on Clean Vehicles is acknowledged. Research assistance was provided by Robb De Kleine and Jason MacDonald of the Center for Sustainable Systems at the University of Michigan.

\section{References}

1. Transportation Energy Data Book: Edition 30 (Report ORNL-6986, Oak Ridge National Laboratory, Oak Ridge, TN, 2011).

2. H.-J. Kim, C. McMillan, G. Keoleian, S.J. Skerlos, J. Ind. Ecol. 14 (6), 929 (2010).

3. Ward's Motor Vehicle Facts \& Figures 2010: Documenting the Performance and Impact of the U.S. Auto Industry (Ward's Communications, Detroit, MI, 2010). 4. Light-Duty Automotive Technology and Fuel Economy Trends: 1975 through 2010 (Report EPA420-S-05-001, U.S. Environmental Protection Agency, Washington, DC, 2011).

5. A. Burnham, M. Wang, Y. Wu, Development and Applications of GREET 2.7-The Transportation Vehicle-Cycle Model (Report ANL/ESD/06-5, Argonne National Laboratory, Argonne, IL, November 2006).
6. "Update Material Production Modules in the GREET 2 Model" (Center for Sustainable Systems, University of Michigan, Ann Arbor, MI, 2011), css.snre. umich.edu/project/update-material-production-modules-greet-2-model.

7. International Aluminium Industry's Perfluorocarbon Gas Emissions Reduction Programme - Update 2009 (International Aluminium Institute, London, 2009).

8. C.A. McMillan, G.A. Keoleian, Environ. Sci. Technol. 43 (5), 1571 (2009).

9. Critical Materials Strategy (U.S. Department of Energy, Washington, DC, December 2010)

10. "Toyota Developing Induction Motors to Break Reliance on China" (Electric Vehicle News, 2011), electric-vehicles-cars-bikes.blogspot.com/2011/01/toyotadeveloping-induction-motors-to.html (accessed 28 October 2011).

11. L. Gaines, P. Nelson, Lithium-Ion Batteries: Possible Materials Issues (Argonne National Laboratory, Argonne, IL, 2008), www.transportation.anl.gov/pdfs/ B/583.PDF (accessed 28 October 2011).

12. R. Geyer, Environ. Sci. Technol. 42, 6973 (2008)

13. P. Gruber, P. Medina, G. Keoleian, S. Kesler, M. Everson, T. Wallington, J. Ind. Ecol. 15 (5), 760 (2011).

14. SAE 2011 Workshop to Characterize Biobased Materials in Vehicles for the USDA BioPreferred Program, Detroit, MI, 15 April 2011.

15. "Head's Up: Ford Increases Soy Content in Foam, Adds Head Restraint as Newest Component for Sustainable Material" (Ford Motor Company, Dearborn, MI, 2011), media.ford.com/article_display.cfm?article_id=35137 (accessed October 2011).

16. A.K. Mohanty, M. Misra, L.T. Drzal, J. Polym. Environ. 10 (1), 19 (2002).

17. J.L. Sullivan, A. Burnham, M. Wang, "Model for the Part Manufacturing and Vehicle Assembly Component of the Vehicle Life Cycle Inventory," J. Ind. Ecol., in press.

18. J.L. Sullivan, A. Burnham, M.Q. Wang, Energy and Carbon Emissions Analysis of Vehicle Manufacturing and Assembly (Technical Report ANL/ESD 10-6, Argonne National Laboratory, Argonne, IL, 2010).

19. C.A. McMillan, S.J. Skerlos, G.A. Keoleian "Evaluation of the Metals Industry's Position on Recycling and Its Implications for Environmental Emissions," J. Ind. Ecol., in press.

20. G.A. Keoleian, G. Lewis, R.B. Coulon, V.J. Camobreco, H.P. Teulon, "LCI Modeling Challenges and Solutions for a Complex Product System: A MidSized Automobile," in Total Life Cycle Conference Proceedings, P-339 (SAE International, Warrendale, PA, 1998), paper no. 982169, pp. 71-84.

21. J.L. Sullivan, R.L. Williams, S. Yester, E. Cobas-Flores, S.T. Chubbs, S.G. Hentges, S.D. Pomper, Life Cycle Inventory of a Generic U.S. Family Sedan Overview of Results USAMP Project (SAE Technical Paper 982160, SAE International, Warrendale, PA, 1998).

22. J.L. Sullivan, J. Hu, Life Cycle Energy Analysis for Vehicles (SAE Technical Paper 951829, SAE International, Warrendale, PA, 1995).

23. K. Bolon, G. Keoleian, L.P. Kostyniuk, Transp. Res. Rec. 2139, 73 (2009). 24. "Waste Reduction" (General Motors, Detroit, MI, 2012), www.gm.com/vision/ waste_reduction_.html (accessed March 2012).

25. "Ford's Sustainable Materials Strategy" (Ford Motor Company, Dearborn, MI, 2012), media.ford.com/images/10031/Ford_Sustainable_Materials_Fact_ Sheet.pdf (accessed March 2012).

26. Directive 2000/53/EC of the European Parliament and of the Council of 18 September 2000 on end-of life vehicles (European Commission, Brussels, Belgium, 2000).

27. V. Kumar, J.W. Sutherland, Int. J. Sustainable Manuf. 1 (1-2), 145 (2008)

28. B.J. Jody, E.J. Daniels, C.M. Duranceau, J.A. Pomykala Jr., J.S. Spangenberger, End-of-Life Vehicle Recycling: State of the Art of Resource Recovery from Shredder Residue (Technical Report ANL/ESD/10-8, Argonne National Laboratory, Argonne, IL, 2010).

29. R.T. Paul, How Prepared Are U.S. Dismantlers to Meet the EU Directive for ELV Recycling? (SAE Technical Paper 2001-01-3744, SAE International, Warrendale, PA, 2001).

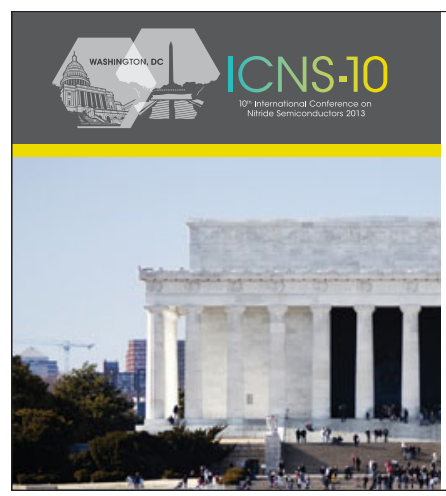

SAVE THE DATE

$10^{\text {th }}$ International Conference on Nitride Semiconductors | August 25-30, 2013

Gaylord National Hotel and Convention Center-Washington, D.C.

Join us for the 10th International Conference on Nitride Semiconductors 2013 (ICNS-10). The conference will present high-impact scientific and technological advances in materials and devices based on group-III nitride semiconductors.

\section{Scientific Program}

The six-day conference will concentrate on the following topical categories:

- Bulk Crystal Growth - Defect Characterization and Engineering

- Epitaxial Growth

- Structural Analysis

- Optical and Electronic Properties - Theory and Simulation

- Processing and Fabrication - Nanostructures

- Light Emitting Devices

- Electron Transport Devices

- Photovoltaics and Energy Harvesting

- New Materials and New Device Concepts

For the most up-to-date information on ICNS-10, visit www.ICNS10.org. 


\section{HD/1/5:/1011 \\ Metals \& Materials}

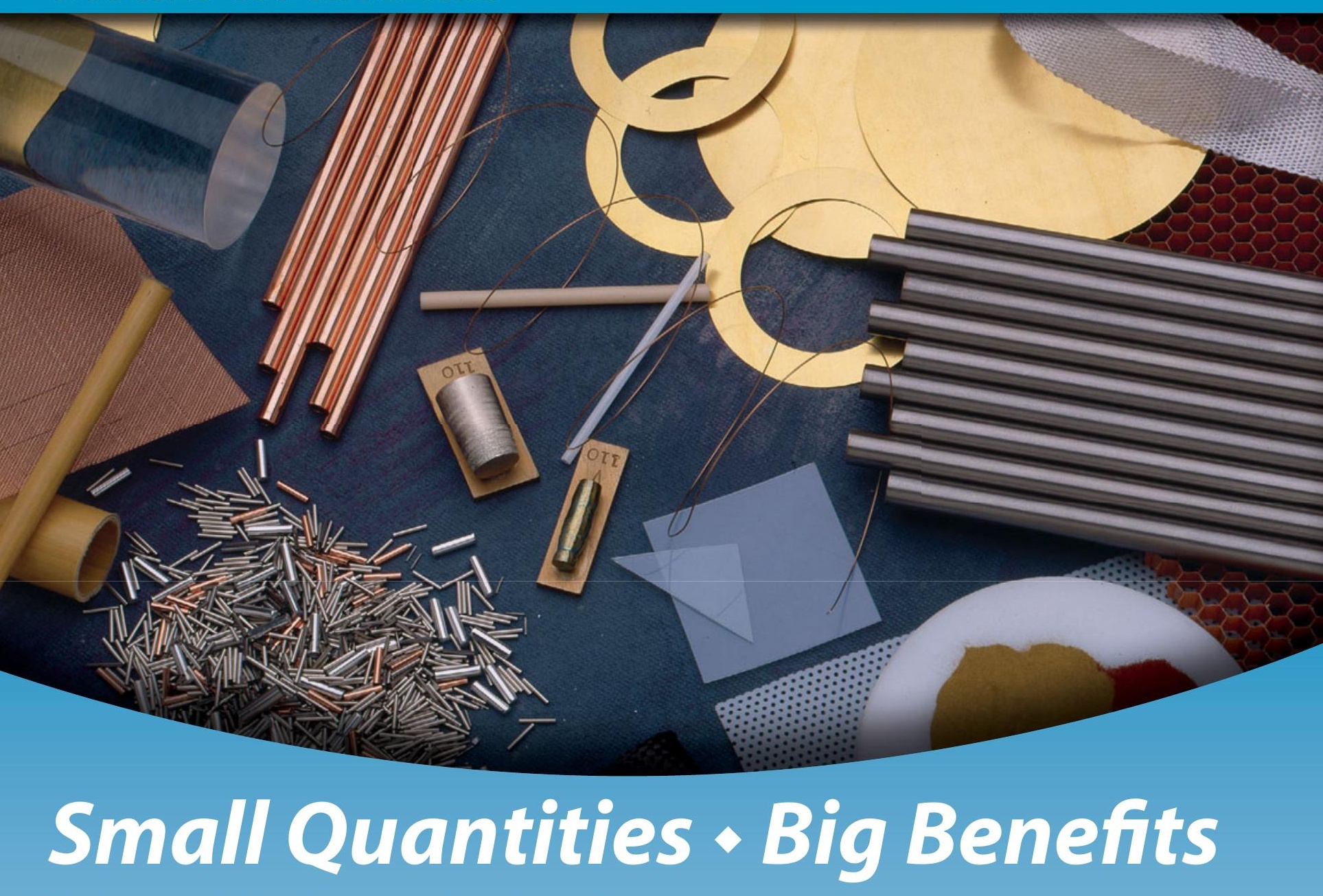

Offering quantities from one piece to small production runs, Goodfellow is your ideal source for metals and materials for research and product design.

- More than 70,000 products at goodfellowusa.com

- An extremely wide range of forms

- Custom finishing, fabrication \& specialized services

- Expert technical assistance

- Outstanding customer service

$\checkmark$ Metals

$\checkmark$ Ceramics, standard \& complex

$\checkmark$ Polymers

$\checkmark$ Composites

$\checkmark$ Specialty \& optical glass NEW

$\checkmark$ Machined ceramic \& glass components ${ }^{N E W}$

We welcome special requests!

It's easy to learn more!

For standard items: goodfellowusa.com

Questions and special requests: info@goodfellowusa.com

To speak to a real live person: 1-800-821-2870 